\title{
Early and Mid-Term Results After Repair of Ischaemic Mitral Regurgitation with Complete Annuloplasty Ring and Incomplete Ring
}

\author{
Rafik F. B. Soliman, MD, FRCSEng(CTH),${ }^{1}$ Morad Beshay Mena, MD,${ }^{2}$ Ahmed M. Elkersh, MD, ${ }^{2}$ \\ Faisl Al Nasser, MD, ${ }^{3}$ Hasan Ibrahim Sandogji, MD ${ }^{3}$ Ayman R. Abdelrehim, MD ${ }^{1,4}$ \\ ${ }^{1}$ Cardiothoracic Surgery Department Faculty of Medicine, Menoufia University, Menoufia, Egypt; \\ ${ }^{2}$ Cardiology Department, Faculty of Medicine, Menoufia University, Menoufia, Egypt; \\ ${ }^{3}$ Cardiac Surgery Department, Madina Cardiac Center, Madina, Saudi Arabia; \\ ${ }^{4}$ Pediatric Cardiac Surgery, Madina Cardiac Center, Madina, Saudi Arabia
}

\section{ABSTRACT}

Background: The choice of ring type for mitral valve (MV) repair is still debatable and usually is left to the surgeon's discretion.

Aim: The aim of this study was to compare the early and mid-term results after repair of ischaemic mitral regurgitation (MR) with complete and incomplete annuloplasty rings.

Methods: Collected data included preoperative assessment (age, sex, comorbidities, clinical status, NYHA grade, and the EURO score); intraoperative details (echocardiography, degree of MR, and cross-clamp time); and results (the length of ICU and hospital stay, duration and need for inotropes, duration of mechanical ventilation, and postoperative adverse events). Follow up after discharge included assessment of dyspnea status, the degree and progression of MR, and left ventricular function and dimensions.

Results: The present study included 133 patients: 61 with incomplete rings and 72 with complete rings inserted. There was no significant difference in the rate of postoperative complications between the two groups, apart from a significantly higher percentage of patients with incomplete ring who required prolonged ventilation $>24$ hours $(P=0.002)$. There were no significant differences between the two groups, regarding the grade of residual $\mathrm{MR}(P=0.464)$, postoperative dyspnea status $(P=0.723), 30$-day mortality rate $(P=0.687)$, and mean duration of survival $(P=0.276)$.

Conclusion: The choice of incomplete or complete annuloplasty ring was not associated with a marked difference in the early and midterm results of ischaemic MV repair.

Received April 14, 2021; received in revised form May 11, 2021; accepted May $11,2021$.

Correspondence: Rafik F. B. Soliman, MD, FRCSEng(CTH), Cardiothoracic Surgery Department Faculty of Medicine, Menoufia University, Menoufia, Egypt (e-mail:rafikfekry@hotmail.com).

\section{INTRODUCTION}

Ischaemic mitral valve regurgitation (MR) occurs commonly in patients suffering from ischaemic heart disease. The development of ischaemic MR has been associated with increased rates of morbidity and mortality [Bursi 2005; Perez 2007], particularly when the degree of regurgitation is severe [Rossi 2011]. The pathophysiology of ischaemic MR involves remodeling of the left ventricle and the subvalvular mitral apparatus, due to myocardial infarction. The papillary muscles are displaced, and the mitral valve annulus becomes dilated, leading to leaflet tethering with a subsequent decrease in leaflet motion, and impaired leaflet coaptation, affecting particularly the posterior leaflet [Kron 2015; Otsuji 2008]. Moreover, MR leads in turn to increased dilatation of the left ventricle and wall stress, thereby a vicious circle develops, resulting in aggravation of the degree of MR and added deterioration of left ventricular function [Dion 1995; Dion 1993].

The best management of ischaemic MR is a matter of debate [Alame 2017]. Simultaneous surgical correction of MR by repair or replacement is recommended in severe cases. The rationale behind mitral annuloplasty is to correct mitral valve insufficiency by restoring the physiological form and function of the healthy mitral valve apparatus [Rausch 2012].

Artificial rings are used for the repair of MR [Alame 2017; Kron 2017]. However, several different types of annuloplasty rings have been developed, with a paucity of evidence to support one type over the other. The types of rings can broadly be classified in terms of flexibility as rigid, semi-rigid, and flexible rings. The rings also vary widely in their shapes but can be categorized as incomplete posterior bands and complete rings. The choice of ring type is principally determined according to the surgeon's judgment [Chee 2008; Yokote 2019].

Consensus guidelines issued by the American Association for Thoracic Surgery recommend using small, undersized, complete, rigid annuloplasty rings in case of moderate or severe ischaemic MR. This recommendation is based on the higher failure rate reported with the use of incomplete and/or flexible bands [Kron 2017].

The present study aimed to compare the early and midterm outcomes after repair of ischaemic MR with complete semi-rigid annuloplasty ring and incomplete flexible ring. 


\section{PATIENTS AND METHODS}

Study settings: This study enrolled patients with ischaemic MR who were referred to Madina Cardiac Center in Saudia Arabia and Cardiotech Cardiac Center and Menoufia University Hospital Egypt from September 2014 to September 2018. Patients' confidentiality was maintained by assigning code numbers to patient data sheets and all study records were kept anonymous.

Patients: From September 2014 to September 2018, 136 patients were referred to our institution for coronary artery bypass graft (CABG) and were found to have grades $3 / 4$ and 4/4 ischaemic MR. All patients were operated on for CABG and mitral valve repair. Complete ring was inserted in 61 patients, while incomplete ring was used for 72 patients. Three patients had a mitral valve replacement; these patients were excluded from our study.

Preoperative assessment was recorded, including age, sex, comorbidities, clinical status (require urgent or elective intervention), the New York Heart Association (NYHA) Functional Classification (grade for dyspnea), left ventricular function and dimensions and the European system for cardiac operative risk EURO score. The degree of MR was defined as mild $(1+)$, moderate (2+), moderate-to-severe (3+), and severe (4+).

Patients were divided into two groups: Group A had complete ring, and Group B had incomplete ring.

Excluded from the study were patients who had previous cardiac surgery or required other concomitant cardiac procedures and those who had MR for reasons other than ischemia.

Surgical technique: Intraoperative transesophageal echocardiography was performed for all patients. Degree of MR was assessed, according to jet area, vena contract, proximal isovelocity surface area (PISA), and flow reversal into the pulmonary vein.

All patients had midline sternotomy and CABG with ascending aorta and bicaval cannulation. Patients' temperature was allowed to drift. Tepid blood antegrade cardioplegia was used. We started with CABG first and then mitral valve was approached and assessed through left atriotomy. All patients had either complete or incomplete annuloplasty ring, based on surgeon's preference to repair the mitral valve.

All operative details, including CABG and cross-clamp time, type of ring (complete or incomplete ring), inotropic support, need for intra-aortic balloon pump (IABP), and degree of residual MR were recorded.

Postoperative data: Length of ICU and hospital stay, duration and need for inotropes, duration of mechanical ventilation, reopening for bleeding or tamponade, postoperative atrial fibrillation (AF), renal failure, and postoperative infection were recorded. Follow up after discharge was documented up to 70 months, including clinical assessment of dyspnea status and echocardiographic assessment of the degree and progression of $M R$ as well as $L V$ function and dimensions.

Statistical analysis: Statistical analysis was performed using Statistical Package for Social Sciences (IBM SPSS Statistics) for Windows, version 26 (IBM Corp., Armonk, NY, USA). For quantitative data, the Shapiro-Wilk test for normality was performed. For data that followed the normal distribution, values were expressed as mean \pm standard deviation.
Comparisons between the two groups were carried out using the Independent Samples T-test. For data that did not follow the normal distribution, median and interquartile range (IQR: expressed as 25 th-75th percentiles) were calculated; MannWhitney test was used to compare between the two groups. For qualitative data, the variables were summarized as count and percentage. Pearson's Chi-square test for independence, Fisher's exact test, or Fisher-Freeman-Halton exact test were used to examine the association between two categorical variables, as appropriate. Survival analysis with KaplanMeier curve and Log-rank test was performed to assess the progression of the severity of residual MR after annuloplasty. A P-value $<0.05$ was adopted to interpret the significance of statistical test results.

\section{RESULTS}

Table 1 summarizes patient characteristics. (Table 1) The incomplete ring group had significantly higher percentages of women $(P=0.024)$, patients with congestive heart failure (CHF) $(P=0.043)$, and dyslipidemia $(P=0.038)$. Patients also had a higher median EURO score $(P=0.036)$.

Table 2 shows the operative data of the included patients. (Table 2) The incomplete ring group had a significantly higher percentage of patients who underwent an urgent operation ( $57.4 \%$ vs. $37.5 \%, P=0.022)$ and those with moderate tricuspid valve insufficiency $(27.9 \%$ vs. $6.9 \%, P=0.001)$. The complete ring group had a significantly longer mean bypass time (141.9 vs. $99 \mathrm{~min}, P<0.001)$ and clamp time (116.4 vs. 84.6 minutes, $P<0.001)$ than the incomplete ring group. There were no significant differences between the two groups, considering the dyspnea status $(P=0.158)$ nor the intraoperative echocardiographic assessment of left ventricular end-diastolic diameter (LVEDD), left ventricular end-systolic diameter (LVESD), and ejection fraction (EF) $(P=0.896, P=0.972$ and $P=0.107$, respectively).

Table 3 shows the postoperative course and follow up of the included patients. (Table 3) A higher percentage of patients with incomplete rings required prolonged ventilation $>24$ hours compared with those with complete rings (39.3\% vs. $15.3 \%, P=0.002)$. No significant difference was detected between the two groups, considering the postoperative length of hospital stay $(P=0.336)$, ICU stay $(P=0.111)$, postoperative LVEDD $(P=0.388), \operatorname{LVESD}(P=0.384)$ and EF $(P=$ $0.293)$, as well as other postoperative complications, including pneumonia $(P=0.374)$, sternal infection $(P=1.000)$, stroke $(P=0.500)$, renal failure $(P=0.101)$, low cardiac output $(P=$ $0.116)$, cardiac arrest $(P=0.977), \mathrm{AF} /$ atrial flutter $(P=0.395)$, and ventricular fibrillation (VF) $(P=1.000)$. Postoperative cardiopulmonary resuscitation was performed in five patients in the incomplete ring group (one patient with PEA, two patients with rapid ventricular tachycardia, and two patients with $\mathrm{VF}$ ) and six patients in the complete ring group (three patients with rapid ventricular tachycardia, one patient with systole, and two patients with VF). There was no significant difference in the grade of residual MR or postoperative dyspnea status between the two groups $(P=0.464$ and $P=0.723$, 
Table 1. Patients' characteristics $(N=133)$

\begin{tabular}{|c|c|c|c|}
\hline \multicolumn{4}{|l|}{ Age (years) } \\
\hline$(\operatorname{Min}-\operatorname{Max})$ & $(16.0-82.0)$ & $(46.0-91.0)$ & \\
\hline \multicolumn{4}{|l|}{ Gender } \\
\hline Male & $56(77.8 \%)$ & $36(59.0 \%)$ & \\
\hline \multicolumn{4}{|l|}{ Co-morbidities } \\
\hline $\mathrm{CHF}$ & $31(43.1 \%)$ & $37(60.7 \%)$ & $0.043 *$ \\
\hline $\mathrm{AF}$ & $17(23.6 \%)$ & $19(31.1 \%)$ & 0.330 \\
\hline IABP & $17(23.7 \%)$ & $19(31.2 \%)$ & 0.330 \\
\hline Diabetes & $51(70.8 \%)$ & $44(72.1 \%)$ & 0.869 \\
\hline Hypertension & 43 (59.7\%) & 35 (57.4\%) & 0.784 \\
\hline Hypothyroidism & $4(5.6 \%)$ & $9(14.8 \%)$ & 0.075 \\
\hline CVA & $8(11.1 \%)$ & $3(4.9 \%)$ & 0.196 \\
\hline PVD & $2(2.8 \%)$ & $5(8.2 \%)$ & 0.246 \\
\hline COPD & $6(8.3 \%)$ & $5(8.2 \%)$ & 0.977 \\
\hline \multicolumn{4}{|l|}{ MR grade } \\
\hline $1+$ & $1(1.4 \%)$ & $0(0.0 \%)$ & 0.301 \\
\hline $2+$ & $7(9.7 \%)$ & $8(13.1 \%)$ & \\
\hline \multicolumn{4}{|l|}{ EuroScore } \\
\hline Median [IQR] & $6.0[4.0-8.0]$ & $7.0[5.0-9.0]$ & $0.036 *$ \\
\hline Min-Max & $(0.0-88.0)$ & $(2.0-16.0)$ & \\
\hline
\end{tabular}

AF, atrial fibrillation; CHF, congestive heart failure; COPD, chronic obstructive pulmonary disease; CVA, cerebrovascular accident; DSL, dyslipidemia; IABP, intra-aortic balloon pump; IQR, interquartile range; Max, maximum; Min, minimum; MV, mitral valve; PVD, peripheral vascular disease; SD, standard deviation; *significant at $P<0.05$

respectively). Death within 30 days after surgery occurred in two and three patients in the incomplete and complete ring groups, respectively. One patient in the complete ring group died after more than 30 days postoperatively. There was no significant difference in mortality between the two groups $(P$ $=0.687)$. The mean duration of survival after surgery did not differ significantly between the two groups $(P=0.276)$.

Figure 1 demonstrates the difference between preoperative and postoperative echocardiographic measurements within each group. (Figure 1) In the complete ring group, LVEDD and LVESD significantly were reduced in follow-up echocardiography compared with preoperative assessment $(P<0.001$ and $P=0.035$, respectively). However, EF increased slightly in the follow-up echocardiography $(P=0.219)$. In the incomplete ring group, the follow-up echocardiography showed a significant reduction in LVEDD and a significant increase in EF $(P=0.005$ and $P=0.046$, respectively), but LVESD was not significantly reduced $(P=0.451)$.

Figure 2 illustrates the Kaplan-Meier curve for the progression of residual MR into grade 3+ or more after annuloplasty. 
(Figure 2) Four patients progressed into grade 3 or 4 (three in the incomplete ring and one in the complete ring group). The Log-rank test showed the lack of significant difference between the two types of rings.

\section{DISCUSSION}

Treatment of moderate and severe ischaemic MR involves repair of the mitral valve and insertion of annuloplasty ring [David 2005; Suri 2006; Fedak 2008]. A wide variety of mitral valve annuloplasty rings have been developed, with variations in flexibility and shape. Several experimental and observational studies assessed the different types of rings and compared between some categories of rings, with discrepancies in the reported results among the studies. The effects of annuloplasty rings on the anatomy of the mitral valve and remodeling of the left ventricle were described, but clinical outcomes in human patients still are not precisely investigated [Khamooshian 2014], particularly in mid-term and long-term follow up.

The present study aimed to compare the early and midterm results between patients undergoing repair of ischaemic MR with complete and incomplete annuloplasty rings. The present study included 133 patients with ischaemic MR: 61 patients with incomplete, flexible rings and 72 patients with complete, semi-rigid rings inserted.

Rigid, complete rings were the first type developed and still are in use. Their design aims at radical reshaping of a

Table 2. Operative details $(N=133)$

\begin{tabular}{|c|c|c|c|}
\hline \multicolumn{4}{|l|}{ Operative status } \\
\hline Elective & 45 (62.5\%) & $26(42.6 \%)$ & $0.022^{*}$ \\
\hline Urgent & $27(37.5 \%)$ & 35 (57.4\%) & \\
\hline \multicolumn{4}{|l|}{ Dyspnea status } \\
\hline Not specified & $0(0.0 \%)$ & $2(3.3 \%)$ & 0.146 \\
\hline NYHA I & $5(7.0 \%)$ & $0(0.0 \%)$ & \\
\hline NYHA II & $19(26.4 \%)$ & $14(23.0 \%)$ & \\
\hline NYHA III & $39(54.2 \%)$ & $33(54.1 \%)$ & \\
\hline NYHA IV & $9(12.5 \%)$ & $12(19.7 \%)$ & \\
\hline Mean \pm SD & $2.7 \pm 0.8$ & $3.0 \pm 0.7$ & 0.059 \\
\hline (Min-Max) & $(1.0-4.0)$ & $(2.0-4.0)$ & \\
\hline TV Insufficiency (moderate + ) & $5(6.9 \%)$ & $17(27.9 \%)$ & 0.001 * \\
\hline \multicolumn{4}{|l|}{$\operatorname{LVEDD}(\mathrm{mm})$} \\
\hline Mean \pm SD & $58.3 \pm 6.5$ & $58.1 \pm 7.5$ & 0.896 \\
\hline (Min-Max) & $(45.0-74.0)$ & $(44.0-74.0)$ & \\
\hline \multicolumn{4}{|l|}{$\operatorname{LVESD}(\mathrm{mm})$} \\
\hline Mean \pm SD & $44.5 \pm 7.4$ & $44.5 \pm 8.8$ & 0.972 \\
\hline (Min-Max) & $(25.0-59.0)$ & $(25.0-63.0)$ & \\
\hline \multicolumn{4}{|l|}{$\mathrm{EF}(\%)$} \\
\hline Mean \pm SD & $39.6 \pm 10.4$ & $36.6 \pm 11.0$ & 0.107 \\
\hline (Min-Max) & $(20.0-60.0)$ & $(18.0-60.0)$ & \\
\hline \multicolumn{4}{|l|}{ Bypass time } \\
\hline Mean \pm SD & $141.9 \pm 50.4$ & $99.0 \pm 39.7$ & $<0.001$ * \\
\hline (Min-Max) & $(0.0-257.0)$ & $(0.0-240.0)$ & \\
\hline \multicolumn{4}{|l|}{ Clamp time } \\
\hline Mean \pm SD & $116.4 \pm 45.5$ & $84.6 \pm 34.9$ & $<0.001$ * \\
\hline (Min-Max) & $(0.0-255.0)$ & $(0.0-194.0)$ & \\
\hline
\end{tabular}

EF, ejection fraction; LVEDD, left ventricular end-diastolic diameter; LVESD, left ventricular end-systolic diameter; Max, maximum; Min, minimum; SD, standard deviation; TV, tricuspid valve; *significant at $P<0.05$ 
Table 3. Postoperative course and outcome $(N=133)$

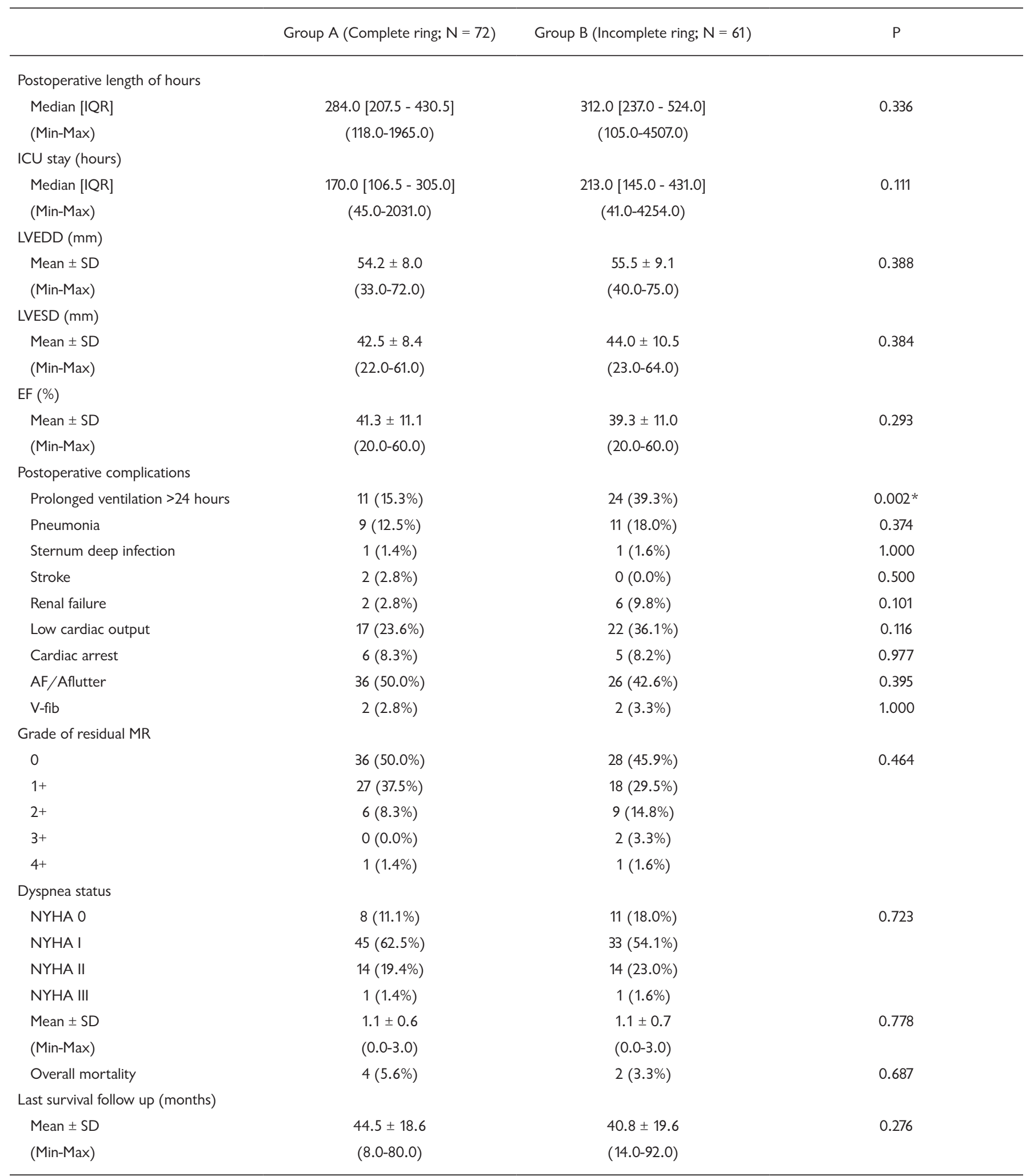

AF, atrial fibrillation; Aflutter, atrial flutter; EF, ejection fraction; ICU, intensive care unit; IQR, interquartile range; LVEDD, left ventricular end-diastolic diameter; LVESD, left ventricular end-systolic diameter; Max, maximum; Min, minimum; MR, mitral regurgitation; SD, standard deviation; V-fib, ventricular fibrillation; *significant at $P<0.05$ 
very dilated mitral valve annulus, which usually occurs with left ventricular dilatation and systolic dysfunction [De Bonis 2011]. Flexible incomplete bands were developed to preserve the contour of the native annulus [Cosgrove 1995]. Semirigid rings were designed, aiming to combine the advantages of rigid and flexible rings, to maintain leaflet coaptation and valve integrity during systole while allowing for physiologic hemodynamic changes during diastole [Carpentier 1995].

The choice of ring type in the present study was based upon surgeon preference. We observed that the use of complete ring significantly was higher among male patients $(P=$ $0.024)$ and those requiring urgent surgery $(P=0.022)$, while the use of incomplete ring significantly was higher in patients with CHF and DSL $(P=0.043$ and $P=0.038$, respectively). Moreover, a significantly higher median EURO score was observed in the incomplete ring group $(P=0.036)$. These findings might explore the surgeons' justification for the type of ring inserted, but further analysis requires a dedicated study, preferably with the interview of surgeons to clarify the reasons beyond their choices and to exclude the probability of ring availability affecting the choice.

The present study assessed the rate of postoperative adverse events. There was no significant difference in the rate of adverse events between the two groups, apart from a significantly higher percentage of patients with an incomplete ring who required prolonged ventilation $>24$ hours $(39.3 \%$ vs. $15.3 \%, P=0.002)$. However, this higher rate may have been affected by differences in patients' comorbidities and basic characteristics. No significant difference was detected between the two groups, considering postoperative length of hospital stay $(P=0.336)$, ICU stay $(P=0.111)$, sternal infection $(P=1.000)$, pneumonia $(P=0.374)$, stroke $(P=0.500)$, renal failure $(P=0.101)$, low cardiac output $(P=0.116)$, cardiac arrest $(P=0.977), \mathrm{AF} /$ atrial flutter $(P=0.395)$, and $\mathrm{VF}$ $(P=1.000)$.

In partial agreement with these results, Pang et al. [Pang 2019] reported the lack of significant difference in the rates of low cardiac output syndrome $(P=0.419)$, respiratory failure $(P=0.730)$, sternal wound infection $(P=0.593)$, and stroke $(P=0.259)$ in their retrospective study on 133 patients with chronic ischaemic MR. However, they found a significantly higher percentage of patients suffering from acute renal failure $(P=0.016)$ in the semi-rigid ring group.

The effect of annuloplasty rings on the measurements and function of the left ventricle is a focus of interest. Our results revealed the lack of significant differences between the two groups, regarding the postoperative LVEDD, LVESD, and $\mathrm{EF}(P=0.388, P=0.384$, and $P=0.293$, respectively). In accordance with our findings, a meta-analysis by $\mathrm{Hu}$ and Zhao [Hu 2011] compared rigid and flexible rings and reported only a slight, not significantly higher LVEDD and LVESD in the flexible ring group in patients with isolated MR. Another meta-analysis by Khamooshian et al. [Khamooshian 2014] included 18 studies and compared rigid, semi-rigid, and flexible annuloplasty rings in patients with ischaemic MR. They found no significant difference in EF, LVEDD, and LVESD among the three types of rings. Similarly, Pang et al. [Pang 2019] reported the lack of significant difference in LVEDD,

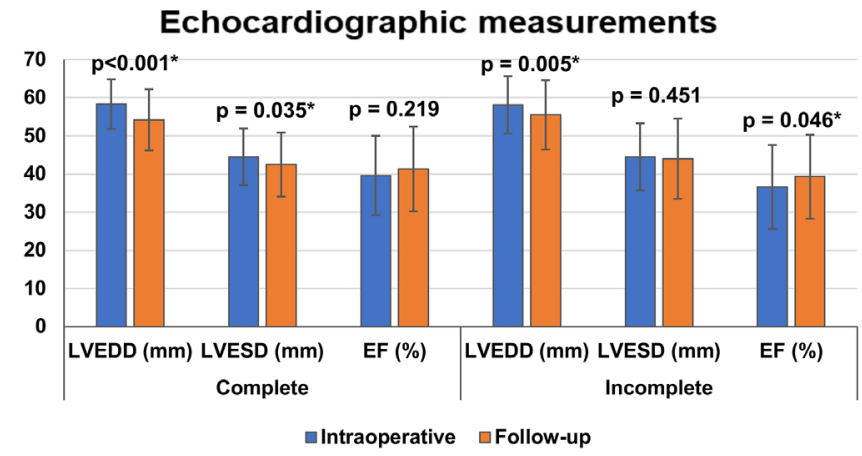

Figure 1. Comparison of intraoperative and follow-up echocardiographic measurements within each group. EF, ejection fraction; LVEDD, left ventricular end-diastolic diameter; LVESD, left ventricular end-systolic diameter. Error bars represent one standard deviation; *significant at $P$ $<0.050$.

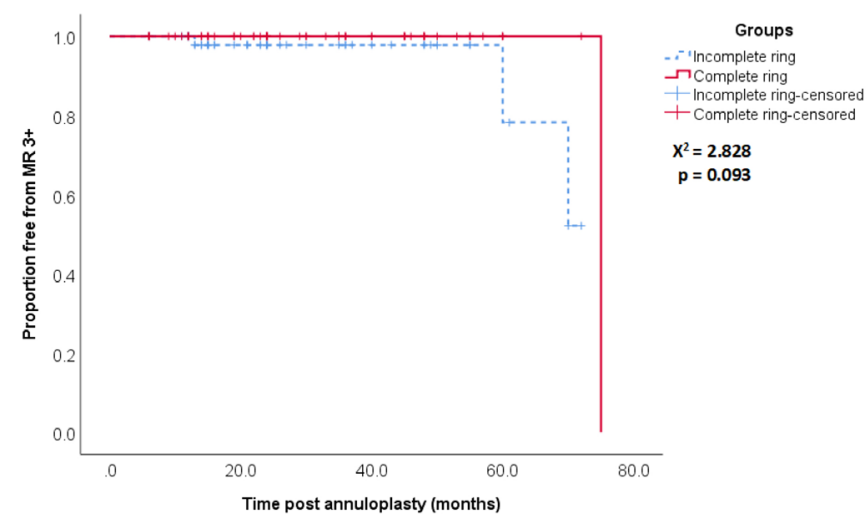

Figure 2. Kaplan-Meier curve for the progression of the grade of residual MR to $3+$ or above. ( $X^{2}$ is the statistic of the Log-rank test)

LVESD, and EF between flexible and semi-rigid ring groups. Regarding the postoperative dyspnea status (defined by the NYHA class), we found no significant difference between the two groups $(P=0.723)$. Khamooshian et al. [Khamooshian 2014] likewise found no significant difference in NYHA class among the rigid, flexible, and semi-rigid ring types, though the mean NYHA class was slightly higher in the flexible ring group.

The difference between preoperative and postoperative echocardiographic measurements was assessed within each group in this study. In the complete ring group, LVEDD and LVESD were reduced significantly in follow-up echocardiography compared with preoperative assessment $(P<0.001$ and $P=0.035$, respectively), while EF showed a slight increase $(P$ $=0.219$ ). In the incomplete ring group, a significant reduction in LVEDD and a significant increase in EF were detected $(P=0.005$ and $P=0.046$, respectively); but LVESD was not significantly reduced $(P=0.451)$. The median postoperative NYHA class showed a significant decrease within each group $(P<0.001)$. Meanwhile, Khamooshian et al. [Khamooshian 2014] found that LVEDD and LVESD decreased significantly 
while EF increased significantly with both flexible and semirigid rings. They found no significant change with the use of rigid rings. They also reported that the mean NYHA score was significantly reduced in all types of rings.

The recurrence of MR grade 3 or above seemed to be higher among the incomplete ring group, though the difference did not reach statistical significance. In partial agreement with this finding, Onorati et al. [Onorati 2009] compared the semi-rigid incomplete and complete rings and found a higher incidence of MR recurrence in the incomplete ring group (64.7\% vs. $10.5 ; P<0.001)$. In addition, Silberman et al. [Silberman 2009] reported that the rate of residual MR with the semi-rigid ring was significantly lower than in the flexible ring group $(15 \%$ vs. $35 \% ; P=0.03)$. Moreover, Pang et al. [Pang 2019] found that the mean grade of residual MR was significantly higher in the flexible ring group compared with the semi-rigid ring group ( 1.40 vs. $0.97 ; P=0.008)$. The stability of mitral valve repair is crucial as heart failure may complicate recurrent MR [Michler 2016; Goldstein 2016]. The entire mitral valve annulus may be distorted by an infarct, so complete ring annuloplasty can provide better results than partial annuloplasty. When the posterior annulus only is stabilized, valve competence may be preserved for a time interval. However, the anterior annulus continues to distort, and the left ventricle continues to remodel, increasing the probability of recurrence of MR [Gorman 2003]. Moreover, incomplete rings do not reduce effectively the septolateral (SL) distance, contributing to the recurrence of MR.

There was no significant difference in 30-day mortality after surgery in our cohort, though the percentage was higher among the complete ring group (5.6\%) compared with the incomplete ring group (3.3\%). The mean duration of survival after surgery did not differ significantly between the two groups $(P=0.276)$. This mortality rate is comparable to the pooled rate of early mortality (5.1\%) reported in a meta-analysis based on seven observational studies and four randomized controlled trials. However, these rates are lower than the rates reported by Saitto et al. [Saitto 2018] and Pang et al. [Pang 2019]. Saitto et al. [Saitto 2018] found operative mortality of $6.6 \%$ and a mortality rate of $22 \%$ in mid-term follow up after insertion of the incomplete, semi-rigid band in 105 patients with ischaemic MR. Pang et al. [Pang 2019] found in-hospital mortality rates of $10.3 \%$ in the flexible ring group and $7.4 \%$ in the semi-rigid ring group, with no significant difference $(P=0.592)$, while the 5 -year and 10 -year patient survival was not significantly higher among the flexible ring group than the semi-rigid ring $(P=0.330)$. On the contrary of these results, Silberman et al. [Silberman 2009] found that a significantly higher 5 -year mortality rate in the flexible, complete ring group (75\%) as opposed to no deaths in the semirigid, complete ring group $(\mathrm{P}=0.03)$.

These variations in mortality rate among the studies could be attributed to differences in basic patients' characteristics as well as the type of ring inserted, in terms of flexibility and/ or shape. Confirmation of the presence or lack of impact of the ring type on patients' survival requires the elimination of confounding factors as in randomized clinical trials and inclusion of a larger sample size.
The current study presented some points of strength as two different types of annuloplasty rings were compared and the follow-up period was fair. However, some limitations appeared. Being an observational study, the effect of basic patients' characteristics, and the involvement of multiple surgeons may affect the choice of ring type and patients' outcomes. A larger sample size and longer follow-up period are required to illustrate whether any difference exists between the ring types, in terms of the long-term outcomes and the stability of the repair.

\section{CONCLUSION}

The choice of incomplete or complete annuloplasty ring was not associated with a marked difference in the early and mid-term results of ischaemic MV repair. However, randomized controlled clinical trials, with larger sample size and a long duration of follow up, are required to confirm or refute these findings.

\section{REFERENCES}

Alame AJ, Karatasakis A, Karacsonyi J, Danek BA, Sorajja P, Gössl M, et al. 2017. Comparison of the American College of Cardiology/American Heart Association and the European Society of Cardiology Guidelines for the Management of Patients With Valvular Heart Disease. The Journal of Invasive Cardiology. 29(9):320-6.

Bursi F, Enriquez-Sarano M, Nkomo VT, Jacobsen SJ, Weston SA, Meverden RA, et al. 2005. Heart failure and death after myocardial infarction in the community: the emerging role of mitral regurgitation. Circulation. 111(3):295-301.

Carpentier AF, Lessana A, Relland JY, Belli E, Mihaileanu S, Berrebi AJ, et al. 1995. The "physio-ring": an advanced concept in mitral valve annuloplasty. Ann Thorac Surg. 60(5):1177-85; discussion 85-6.

Chee T, Haston R, Togo A, Raja SG. 2008. Is a flexible mitral annuloplasty ring superior to a semi-rigid or rigid ring in terms of improvement in symptoms and survival? Interactive Cardiovascular and Thoracic Surgery. 7(3):477-84.

Cosgrove DM, 3rd, Arcidi JM, Rodriguez L, Stewart WJ, Powell K, Thomas JD. 1995. Initial experience with the Cosgrove-Edwards Annuloplasty System. Ann Thorac Surg. 60(3):499-503; discussion -4.

David TE, Ivanov J, Armstrong S, Christie D, Rakowski H. 2005. A comparison of outcomes of mitral valve repair for degenerative disease with posterior, anterior, and bileaflet prolapse. The Journal of Thoracic and Cardiovascular Surgery. 130(5):1242-9.

De Bonis M, Taramasso M, Grimaldi A, Maisano F, Calabrese MC, Verzini A, et al. 2011. The GeoForm annuloplasty ring for the surgical treatment of functional mitral regurgitation in advanced dilated cardiomyopathy. European Journal of Cardiothoracic Surgery: official journal of the European Association for Cardio-thoracic Surgery. 40(2):488-95.

Dion R. 1993. Ischemic mitral regurgitation: when and how should it be corrected? The Journal of Heart Valve Disease. 2(5):536-43.

Dion R, Benetis R, Elias B, Guennaoui T, Raphael D, Van Dyck M, et al. 1995. Mitral valve procedures in ischemic regurgitation. The Journal of Heart Valve Disease. 4 Suppl 2:S124-9; discussion S9-31. 
Fedak PW, McCarthy PM, Bonow RO. 2008. Evolving concepts and technologies in mitral valve repair. Circulation. 117(7):963-74.

Goldstein D, Moskowitz AJ, Gelijns AC, Ailawadi G, Parides MK, Perrault LP, et al. 2016. Two-Year Outcomes of Surgical Treatment of Severe Ischemic Mitral Regurgitation. N Engl J Med. 374(4):344-53.

Gorman JH, 3rd, Gorman RC, Jackson BM, Enomoto Y, St John-Sutton MG, Edmunds LH, Jr. 2003. Annuloplasty ring selection for chronic ischemic mitral regurgitation: lessons from the ovine model. Ann Thorac Surg. 76(5):1556-63.

Hu X, Zhao Q. 2011. Systematic evaluation of the flexible and rigid annuloplasty ring after mitral valve repair for mitral regurgitation. European Journal of Cardiothoracic Surgery: official journal of the European Association for Cardio-Thoracic Surgery. 2011;40(2):480-7.

Khamooshian A, Buijsrogge MP, de Heer F, Gründeman PF. 2014. Mitral valve annuloplasty rings: review of literature and comparison of functional outcome and ventricular dimensions. Innovations (Philadelphia, Pa). 9(6):399-415.

Kron IL, Hung J, Overbey JR, Bouchard D, Gelijns AC, Moskowitz AJ, et al. 2015. Predicting recurrent mitral regurgitation after mitral valve repair for severe ischemic mitral regurgitation. The Journal of Thoracic and Cardiovascular Surgery. 149(3):752-61.e1.

Kron IL, LaPar DJ, Acker MA, Adams DH, Ailawadi G, Bolling SF, et al. 2017. 2016 update to The American Association for Thoracic Surgery (AATS) consensus guidelines: Ischemic mitral valve regurgitation. The Journal of Thoracic and Cardiovascular Surgery. 153(5):e97-e114.

Michler RE, Smith PK, Parides MK, Ailawadi G, Thourani V, Moskowitz AJ, et al. 2016. Two-Year Outcomes of Surgical Treatment of Moderate Ischemic Mitral Regurgitation. N Engl J Med. 374(20):1932-41.

Onorati F, Rubino AS, Marturano D, Pasceri E, Mascaro G, Zinzi S, et al. 2009. Mid-term echocardiographic results with different rings following restrictive mitral annuloplasty for ischaemic cardiomiopathy. European Journal of Cardio-Thoracic Surgery: official journal of the European Association for Cardio-Thoracic Surgery. 36(2):250-60; discussion 60.
Otsuji Y, Levine RA, Takeuchi M, Sakata R, Tei C. 2008. Mechanism of ischemic mitral regurgitation. Journal of Cardiology. 51(3):145-56.

Pang PYK, Huang MJ, Tan TE, Lim SL, Naik MJ, Chao VTT, et al. 2019. Restrictive mitral valve annuloplasty for chronic ischaemic mitral regurgitation: outcomes of flexible versus semi-rigid rings. Journal of Thoracic Disease. 11(12):5096-106.

Pérez de Isla L, Zamorano J, Quezada M, Almería C, Rodrigo JL, Serra $\mathrm{V}$, et al. 2007. Functional mitral regurgitation after a first non-ST-segment elevation acute coronary syndrome: contribution to congestive heart failure. Eur Heart J. 28(23):2866-72.

Saitto G, Lio A, Russo M, Nicolò F, Bassano C, Scafuri A, et al. 2018. Mitral Valve Repair with a Semi-Rigid C-Band Annuloplasty Ring in Ischemic Mitral Regurgitation: Still a Viable Surgical Option? The Journal of Heart Valve Disease. 27(1):47-54.

Silberman S, Klutstein MW, Sabag T, Oren A, Fink D, Merin O, et al. 2009. Repair of Ischemic Mitral Regurgitation: Comparison Between Flexible and Rigid Annuloplasty Rings. The Annals of Thoracic Surgery. 87(6):1721-7.

Suri RM, Schaff HV, Dearani JA, Sundt TM, 3rd, Daly RC, Mullany CJ, et al. 2006. Recurrent mitral regurgitation after repair: should the mitral valve be re-repaired? The Journal of Thoracic and Cardiovascular Surgery. 132(6):1390-7.

Rausch MK, Bothe W, Kvitting JP, Swanson JC, Miller DC, Kuhl E. 2012. Mitral valve annuloplasty: a quantitative clinical and mechanical comparison of different annuloplasty devices. Annals of Biomedical Engineering. 40(3):750-61.

Rossi A, Dini FL, Faggiano P, Agricola E, Cicoira M, Frattini S, et al. 2011. Independent prognostic value of functional mitral regurgitation in patients with heart failure. A quantitative analysis of 1256 patients with ischaemic and non-ischaemic dilated cardiomyopathy. Heart (British Cardiac Society). 97(20):1675-80.

Yokote J, Araki Y, Saito S, Hasegawa H, Usui A. 2019. Effect of an artificial ring on mitral valve function. Nagoya Journal of Medical Science. 81(2):207-15. 